\title{
Effect of soil amelioration and supplementary foliar nutrition on rice yield in Kuttanad, Kerala
}

\section{S. Lekshmi and V. Mini}

\section{MEMBERS OF RESEARCH FORUM: \\ Corresponding author : \\ S. Lekshmi, Department of Soil Science and Agricultural Chemistry, College of Agriculture, Vellayani, Thiruvananthapuaram (Kerala) India}

Co-authors :

V. Mini, Onattukara Regional Agricultural Research Station, (KAU), Kayamkulam (Kerala) India
Received : 30.07.2018; Revised : 03.11.2018; Accepted : 12.11 .2018

\section{Summary}

Kuttanad is a unique wetland ecosystem lying 0.6 to $2.2 \mathrm{~m}$ below the mean sea level. The soil of Kuttanad is characterised by extreme acidity and accumulation of salts and the cultivation of paddy in this area faces problems due to water logging, acidity and metal toxicities of iron and aluminium. Iron toxicity can cause nutrient disorders and deficiencies of several elements like $\mathrm{P}, \mathrm{K}, \mathrm{Ca}, \mathrm{Mg}, \mathrm{Mn}$, and $\mathrm{Zn}$ and primarily affects the production of lowland rice. Management strategies such as liming and additional multi nutrient supply (P, K, Mg, $\mathrm{Zn}, \mathrm{Cu}$ and $\mathrm{B}$ ) have proven to enhance the rice productivity of soils prone to Fe toxicity by correcting the multi nutrient deficiencies. Therefore, this study was undertaken with the objectives to evaluate the effect of soil amelioration with rice husk ash in abating iron toxicity and supplementary foliar application of a customized nutrient formulation in increasing rice yield in the low lands of Kuttanad. A customized nutrient formulation was developed based on the available nutrient status of the region and crop requirement and applied as foliar spray of 0.5 per cent solution in two splits at maximum tillering and panicle initiation stage. The field experiment was done at Rice Research Station, Moncompu using rice variety Uma. The experiment was laid out in RBD with nine treatments and three replications. The results indicated that use of rice husk ash as soil ameliorant along with soil test based RDF and supplementary foliar nutrition improved rice yield in Kuttanad and reduced the nutritional constraints due to iron toxicity.

Key words : Soil amelioration, RHA, Foliar nutrition, Customized formulation

How to cite this article : Lekshmi, S. and Mini, V. (2018). Effect of soil amelioration and supplementary foliar nutrition on rice yield in Kuttanad, Kerala. Asian J. Soil Sci., 13 (2) : 99-103 : DOI : 10.15740/ HAS/AJSS/13.2/99-103. 